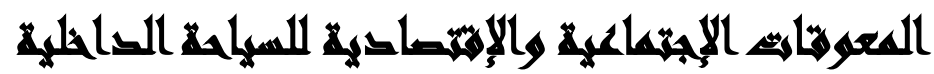

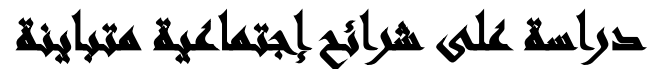

\section{[1.]}

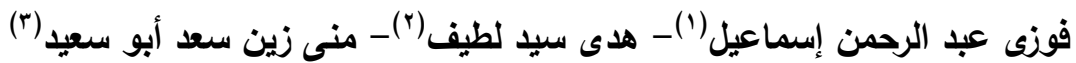

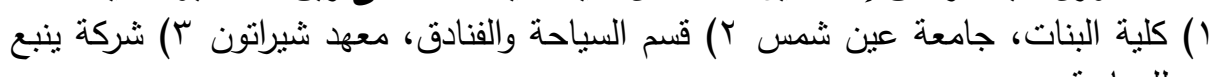
لل السباحة.

\section{المستخلت}

تهدف الدراسة إلى التعرف على المعوقات الإجتماعية والإقتصادية للسياحة الداخلية، تعد

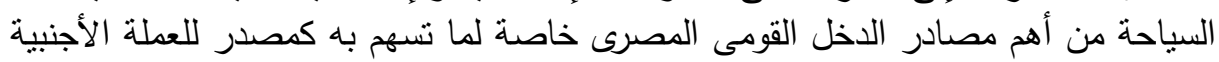

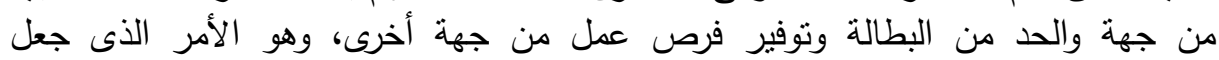

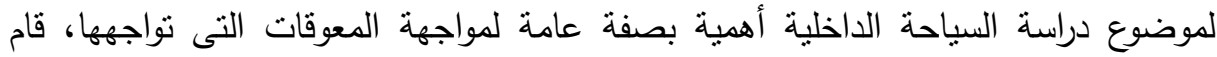

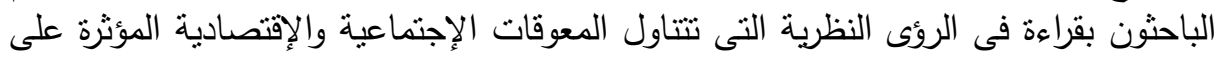

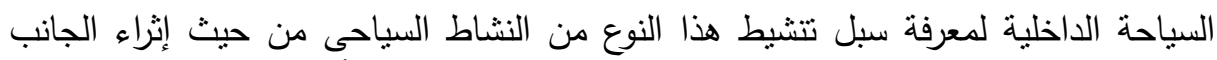

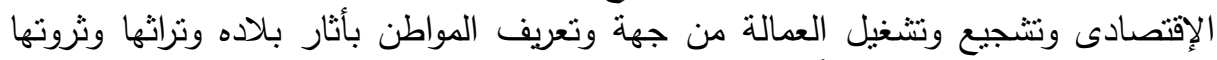

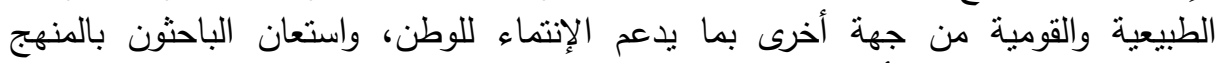
الوصفى التحليلى وكانت أدواتها الإسنتيان والمقابلة.

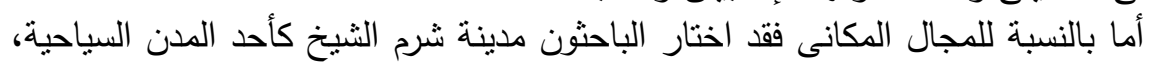

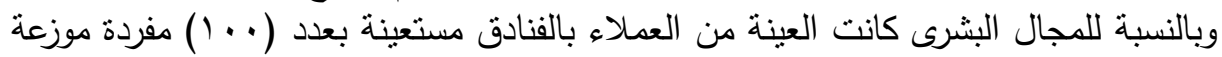

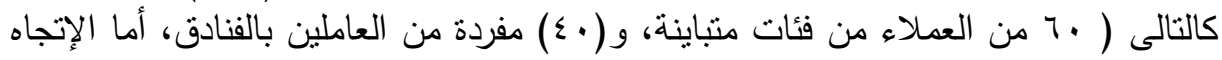
النظرى الذى إنطلقت منه الدراسة فهو البناء البنائية الوظيفية.

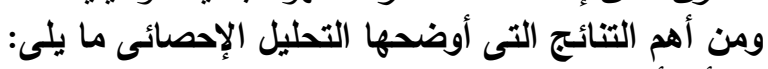

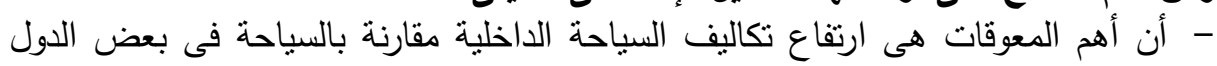
بالمنطقة. - تدنى مسنوى المعاملة التى يلقاها السائح المصرى مقارنة بنظيره الأجنبى.

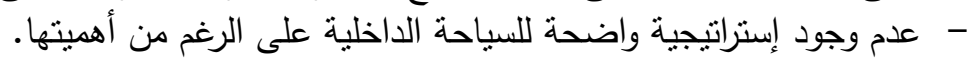

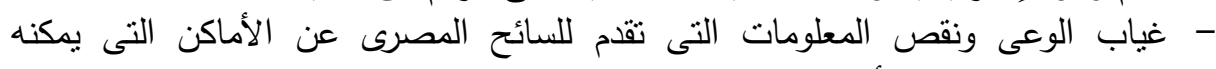
زيارتها، وعن خطط الأسعار . 
- توصى الدراسة بالإهتمام بوضع إستراتيجية عامة وشاملة للنشاط السباحى بما بحقق

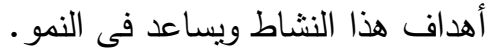

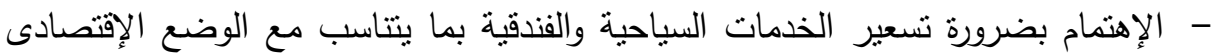
للمواطن المصرى ويشجعه على السياحة الداخلية.

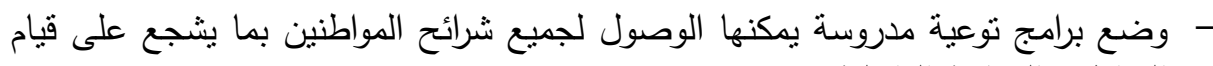
المواطن بالسياحة الداخلية.

\section{anaball}

تعد السياحة أحد أهم الركائز الأساسية فى إقتصاديات الدول المتقدمة وخاصة لدى

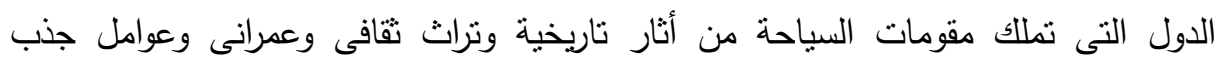
مختلفة كالعوامل المناخية والمناظر الطبيعية والثواطئ الجذابة، وتعد مصر على رلى رأس قائمة الدول التى تملك جل هذه المقومات إن لم تكن كلها . ويعد وجود إستراتيجية واضحة للنشاط السياحى ورؤية شاملة لإستغلال الإمكانات

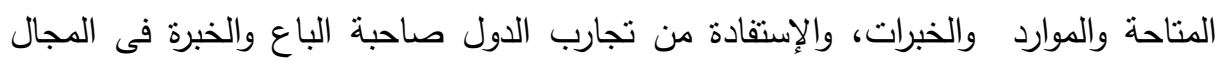
السياحى، هى من أهم آليات تتشيط السباجة الداخلية والخارجية، بما تشمله الروئية

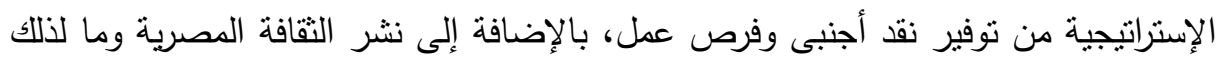
من نأثثر على كافة النواحى الإقتصادية والإجتماعية والسياسية والثقافية.

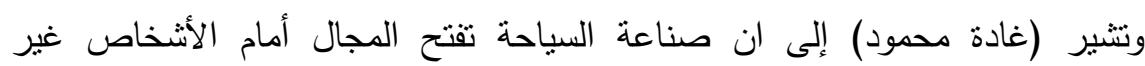

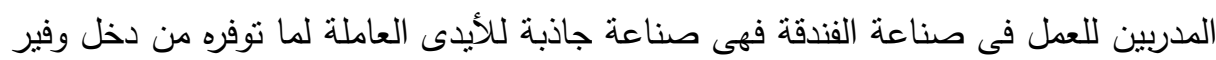

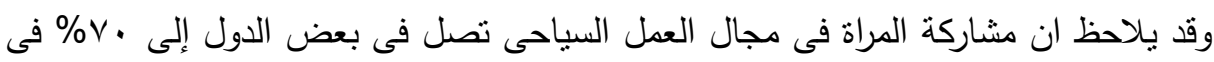

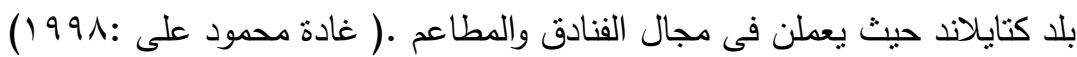
ومن حيث المحافظة على البعد البيئى تعمل السياحة على تطبيق مفهوم أن السائح

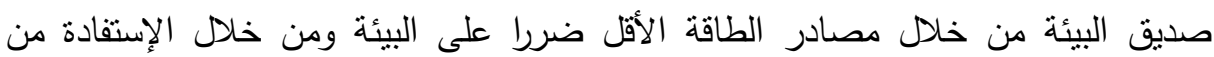

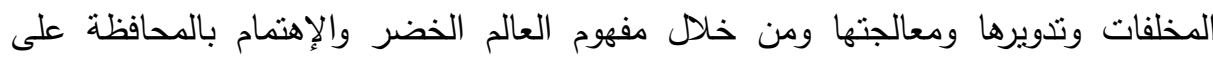
الطبيعة، كما تعتبر صناعة الفندقة من أقل الصناعات ضررا على البيئة مقارنة بالصناعات 
الأخرى.( وفاء أحمد عبد الله : rي19 (الح )

ومن الجدير بالذكر أن صناعة الفندقة هى الأساس والجزء الحيوى فى صناعة الهياه السياحة

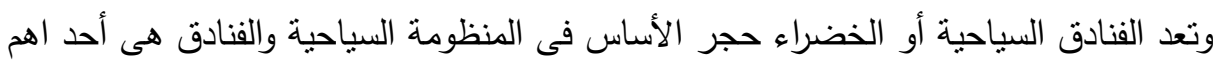
مستلزمات السياحة الحديثة، ولا يمكن وجود بلد متحضر بدون فندق ( 2002. Slattery). والسياحة بفضل انها تحسن الإنشاءات وتقدم وتتظيم الهيئات العمالية، أدى لأن تصبح

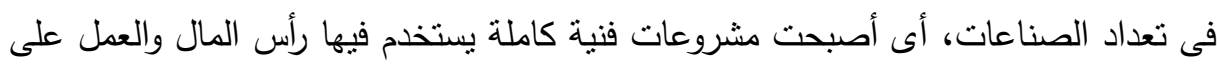

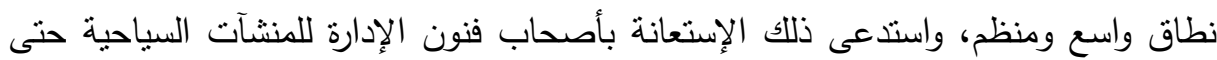
أصبحت الفندقة فن يجذب الإستثمارات. ( Hiemastra,1995) ومن حيث أهمية الوعى وجد أن كثيرا من الدول المتقدمة فى النواحى السياحية إهتمت

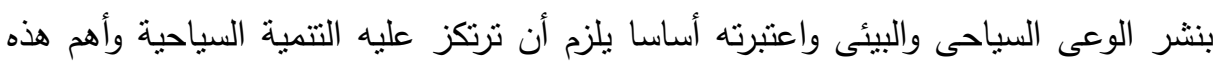

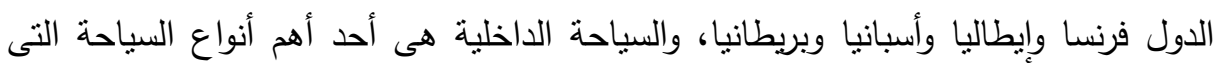

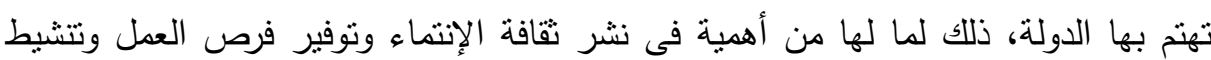

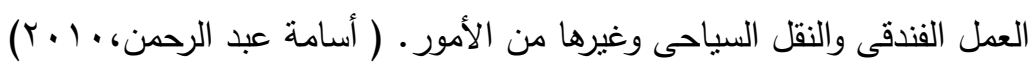
وترى الدراسة أن هذا النوع من السياحة يواجه بعض المعوقات الإجتماعية والإقتصادية

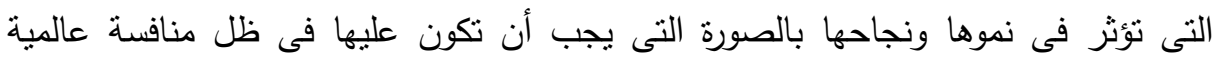

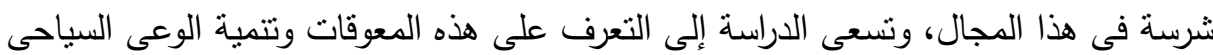

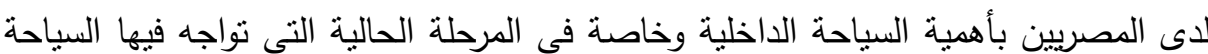
المصرية أثند أزماتها فى العصر الحديث.

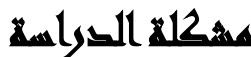

تعد السياحة أحد أهم مصادر الدخل القومى للعديد من الدول ومنها مصر، ولكنها لا تحصل على الإهتمام اللازم من الدولة ومتخذ القرار يتتاسب مع هذا القدر من الأهمية. لذا تعانى السياحة فى مصر الكثثر من المشكلات والمعوقات التى تؤثر سلبا على هذا

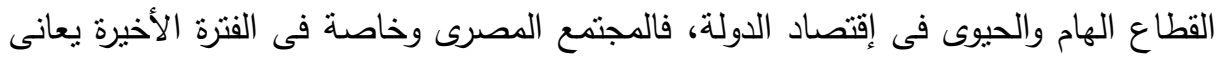

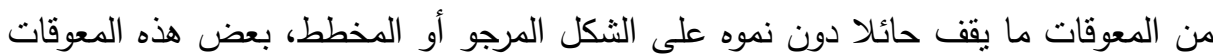

$$
\text { المجلد الثالث والثلاثثون، الجزء الثالث، يونيو } 17 \text {. }
$$


ذات بعد رسمى مرتبط بتعامل المنظومة الحكومية مع قضايا السياحة، من إهمال فى تتمية

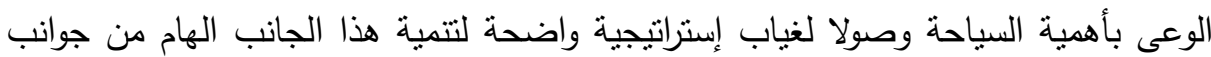

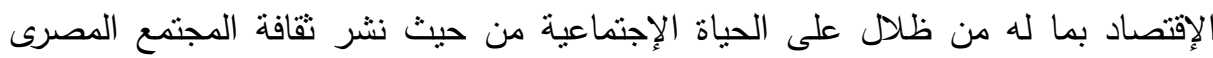
والإستفادة من الإحتكاك التقافى إلى نوفير فرص عمل نساعد فى إعالة أكثر من مليونى

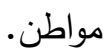

وتتشير وفاء إبراهيم : ج . . r، إلى أن معرفة وتحديد هذه المعوقات والعوامل المؤدية إليها يساعد على وضع خطة للتغير تساهم فى تحقيق أهداف هذا النشاط على المستوى الإجتماعى إنى والثقافى والإقتصادى والنفسى. ( وفاء زكى إبراهيم : ج . . ب).

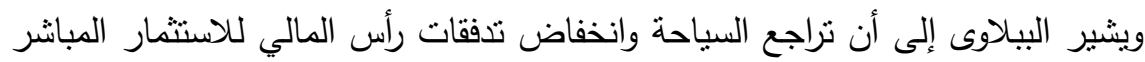
أو التوظيف في السوق المالية مع خروج بعض هذه الأموال إلى الخارج، وقد أدى كل ذلك للك

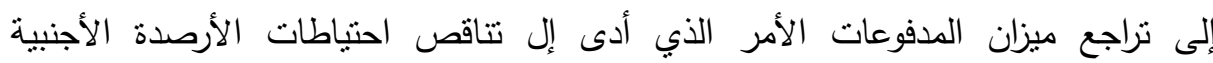

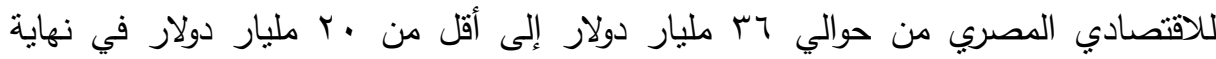

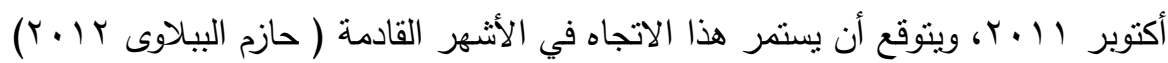

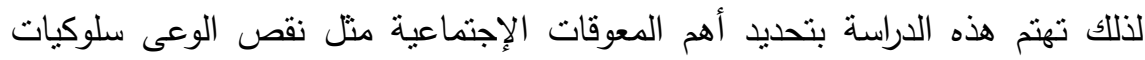

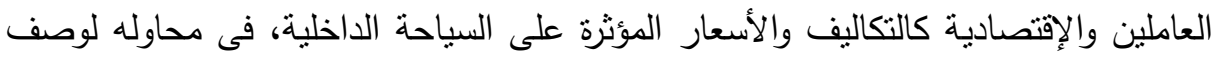
وتقسير هذه المعوقات وتقديم توصيات لتلافيها وتتمية هذا القطاع الإقتصادى الحيوى الهام.

\section{تمساولائ الصراسلة}

() ما المعوقات الاجتماعية التى تواجه السياحة الداخلية فى مصر؟

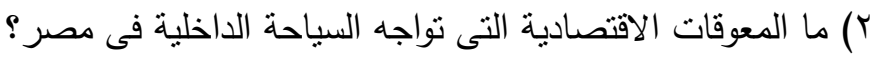

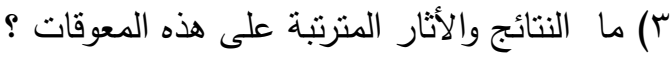

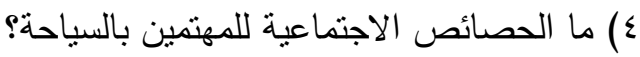

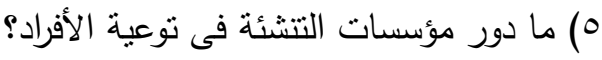

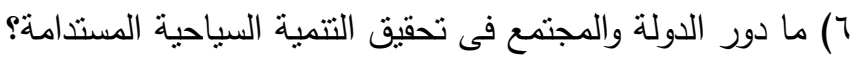


( ) ما دور التتمية المستدامة فى تحقيق استثمار أفضل للسياحة الداخلية؟ ^) ما المقترحات التى يمكن صياغتها لتعزيز إيجابيات التتمية السياحية مع الحد من أنثار تلأك

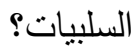

\section{أهساهثم الصراسة}

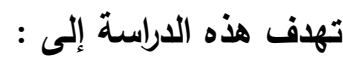

( ) تحديد أهم المعوقات الإجتماعية والإقتصادية التى تؤئز على السياحة فى مصر .

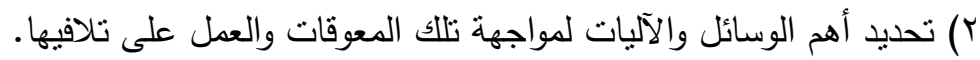

r) وضع روئة علمية لكيفية وضع إستراتيجية للنهوض بالسياحة الداخلية. ع) الكثف عن المشاكل التى تعوق السياحة الداخلية وتوضح التأثير المنبادل بين التتمية السياحية والإهتمام بالبيئة.

\section{أهمهية الصوراهم}

تكمن أهمية الدراسة الحالية فى النقاط التالية: () تعتبر مصر من البلدان السياحية الهامة التى تمنل السياحة فيها المصدر الثانى للعملة الأجنبية بعد قناة السويس مما يجعل الدراسات فى هذا المجال لها قدرا كبيرا من الأهمية.

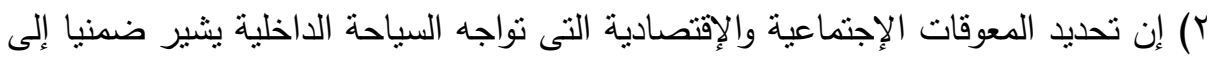
أهمية تفعيل دور المواطنين والسائحين الاجانب فى الحفاظ على المناطق الأثرية.

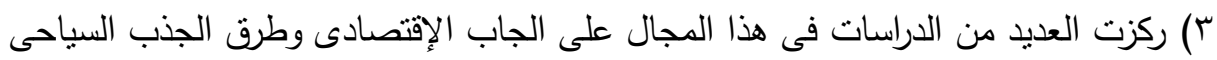
بينما تحاول هذه الدراسة تتاول جوانب أخرى كالنواحى الإقتصادية والإجتماعية والمعوقات

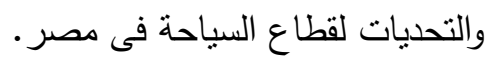

ع) تؤكد الدراسة على أهمية زيادة الوعى السياحى عند المصريين، مع التأكيد على أهية

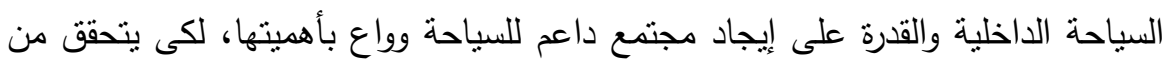

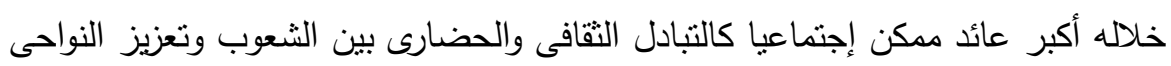




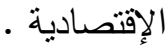

\section{مفاسهيو التراسة}

تناولت الدراسة مجموعة من الفاهيم بالتوضيح أهمها (مفهوم السياحة - السياحة

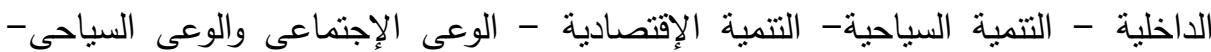

العوامل الإقتصادية - العوامل الإجتماعية)

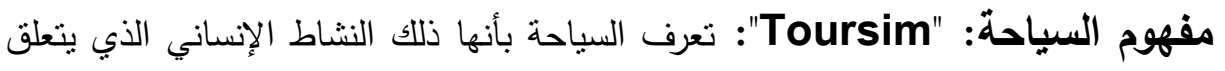

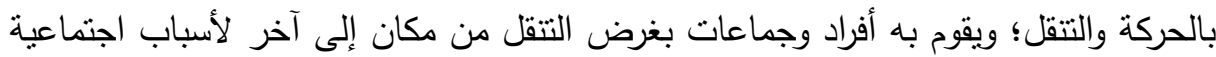

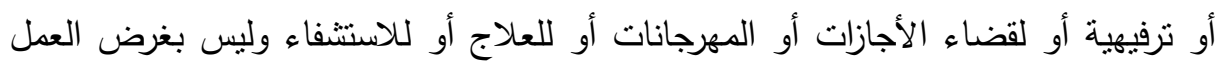

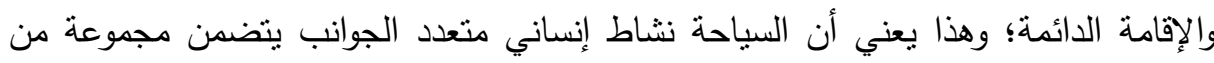
العلاقات المتبادلة بين السائح الذي يوجد بصفة مؤقتّة فقط في مكان إقامته وبين الأنتخاص

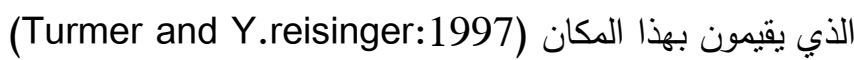
مفهوم السياحة الداخلية: تبلغ السياحة الداخلية في الدول المتقدمة من ثمانية إلى تسعة

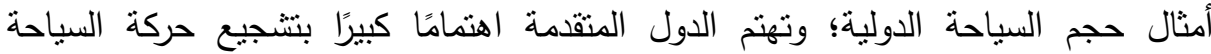
الداخلية وتقديمها كخدمة ضرورية ولذلك يجب توفير كل الدعائم والمقومات للسائحين

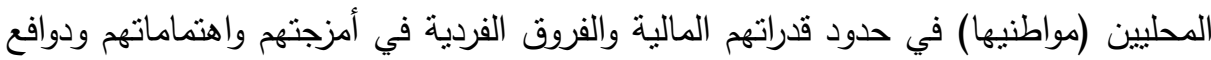

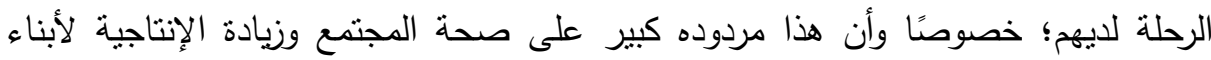

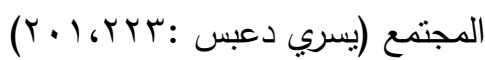

مفهوم التنمية السياحية: الدفوم الاصطلاحي للتتمية السياحية وهو أن بدأت تتبلور الأفكار في تحديد مفهوم السياحة مع بداية القرن العشرين حيث عرفت بأنها ظاهرة عصرية الإنها

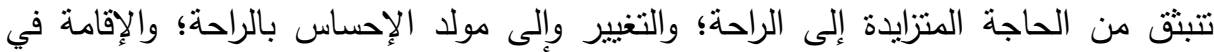
مناطق لها طبيعتها الخاصة؛ ونمو الاتصالات بين الثنعوب، وهي ثمرة التساع نطاق التهات التجارة والصناعة وتقدم وسائل النقل وبهذا فإن للسياحة بعد اجتماع ناتج عن زيادة أوقات الفراغ الفاء؛ والحاجة إلى الدتعة؛ والإقامة بعيدًا عن محل السكن دون تحديد إطار الحركة؛ وطول المسافة؛ 


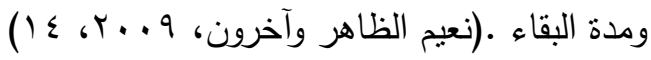

مفهوم التتمية الاقتصادية: إن التتمية الاقتصادية هي عملية متواصلة؛ نساهم في زيادة الدخل القومي للبلاد إلا أن الزيادة المطردة في المكان والمنافسة الثديدة بين الأنشطة المختلفة

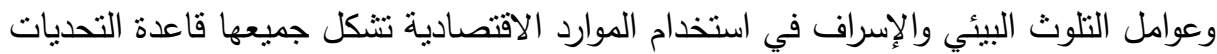
التي تقف في مواجهتها مجموعة من الأهداف والتي تتمثل في المحافظة على الموارد المتوفرة وتتميتها والعمل على زيادة كمياتها والحد من التلوث وتحسين نوعيته .(مصطفى يوسف

كافي: مفهوم البيئة الاقتصادية: ويعرف اقتصاد البيئة بأن تدور مشكلة الاقتصاد حول ما هو مشاهد في الحياة الواقعية من ندرة نسبية في الموارد القابلة لإثباع الحاجات المختلفة، مما يحتم عليه استخدامها على أفضل نحو مستطاع حتى يمكنه الوصول إلى أقصى إنباع وما

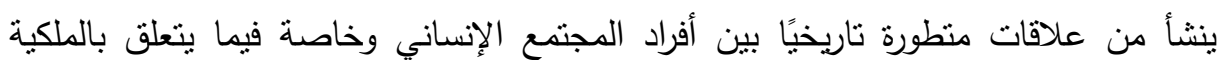

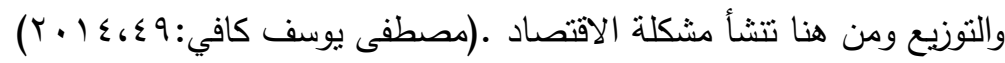
مفهوم الوعي الاجتماعي: الوعي الاجتماعي هو المجموع الكلي للأفكار والنظريات والآراء والمشاعر والعادات والتقاليد الموجودة في المجتمع؛ وتعد علاقات الإنتاج القائمة بين

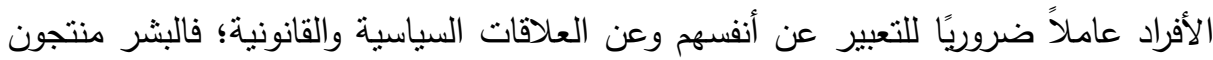

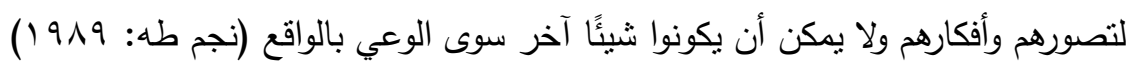

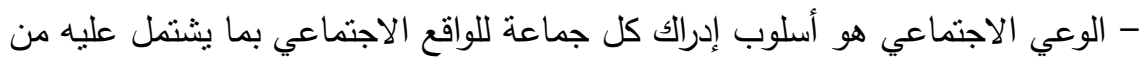
علاقات ونظم وفهمه لما يدور فيه من أحداث وتقييمهم لها وردود أفعالهم تجاهها(فهي عادل، (1990) مفهوم الوعي السياحي :الوعي السياحي يعد شكلاً جديدًا من أشكال الوعي الاجتماعي، ظهر نتيجة نوسع نشاط الإنسان وحاجاته ومتطلباته؛ فالوعي السياحي هو إدراك الفرد وفهمه

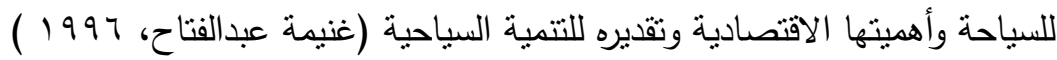
والوعي السياحي أيضًا هو جملة من آداب السلوك والتعامل مع السائح واحترامه وعدم استغلاله والتضييق عليه أو النظر إليه على أنه مصدر للربح؛ إنما هو ضيف كريم(نوفل،

$$
\text { المجلد الثالث والثلاثثون، الجزء الثالث، يونيو } 17 \text {. }
$$


مفهوم العوامل الاقتصادية: وتعرف بأنها شكل الإنتاج؛ التوزيع الاستهلاك، نظام الملكية، التصنيع وتلعب هذه العوامل الاقتصادية دورًا هامًا في إحداث التغير حيث يرتبط العامل الاقتصادي بعوامل أخرى كالسكان والبيئة التكنولوجية وقد يكون العامل الاقتصادي الأسبقية في إحداث التغير والتعجيل به ألا أنه لا يكون العامل الوحيد المسبب للتغير (جمال عبدالكريم

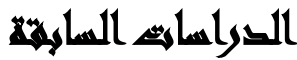

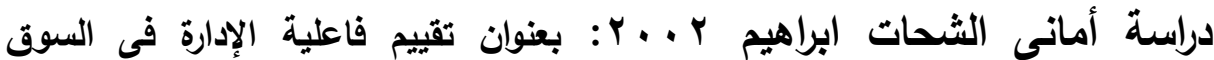
السياحى المصرى، هدفت الدراسة إلى تقييم فاعلية الإدارة فى السوق السياحى الدصرى. تتاول البحث المفاهيم الإدارية ومكونات السوق السياحى والمتغيرات السياسية والاقتصادية المؤثرة على الأداء الإدارى، وتقييم الأداء الإدارى ومعوقات الفاعلية الإدارية. أجريت دراسة ميدانية

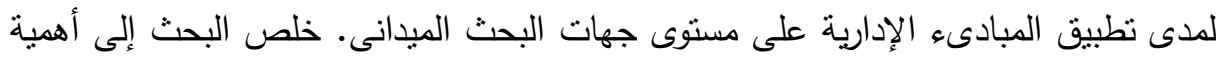
تدريب العاملين بالنظام السياحى، واختيار الكوادر الإدارية، مع وضع نظام لتقييم الأداء الإدارى والمحافظة على مستويات الأداء المرتفع والمتميز لدى جهات البحث الميدانى.

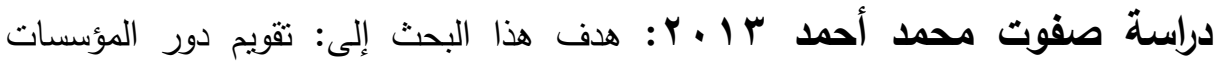
الاقتصادية فى رعاية السياحة الرياضية بمصر وتقديم نموج مقترح للمؤسسات الاقتصادية لرعاية مهرجانات السياحة الرياضية من خلال التعرف على أهداف المؤسسات الاقتصادية من التهايه رعاية مهرجانات السياحة الرياضية بمصر ، والمعوقات التى تواجه المؤسسات الاقتصادية عند رعاية مهرجانات السياحة الرياضية بمصرمستخدماً المنهج الوصفي، وعينة مكونة من ــ من

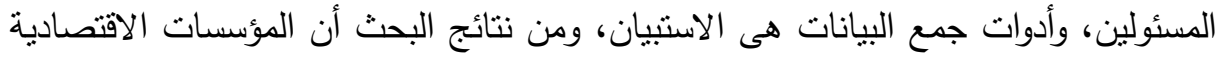
تسعى إلى زيادة شهرتها من خلال تشجيع ودعم مهرجانات السياحة الرياضية وذللك تأكيدا على المسئولية الاجتماعية للمؤسسات الاقتصادية مستخدمة وسائل العرض فى وسائل الإعلام 
ولا تسعى إلى احتكار عمليات الرعاية لمهرجانات السياحة الرياضية ومهرجانات السياحة الرياضية العالمية تحظى براعية المؤسسات الاقتصادية عن المهرجانات المحلية. دراسة أسماء محمد أحمد ه 1 ـ ب بعنوان دور التسويق السياحي في إدارة الأزمات في مصر، وقد خلصت الدراسة إلى ضرورة إنثاء قسم لإدارة الأزمات مستقل بذاته لأن صناعة

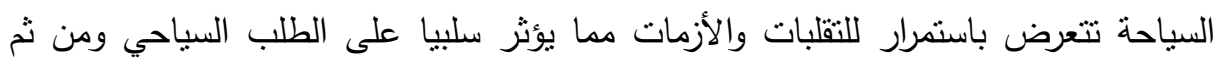
الدخل القومي في مصر ، وإلى التأكيد على استمرار التتسيق بين أجهزة السياحة الرسمية وكافة

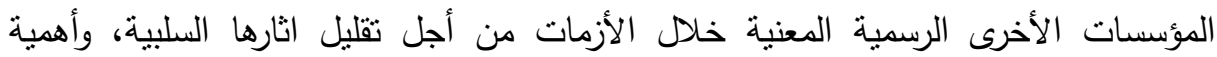

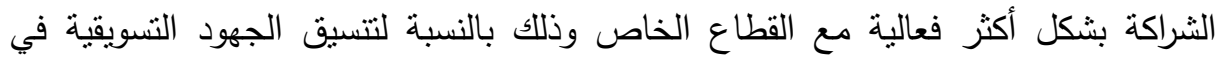
إعداد الحملات التسويقية وتحمل التكاليف المادية المطلوبة، بالإضافة إلى إمكانية تكثيف الترويج عبر الاتنرنت وخاصة مواقع التواصل الاجتماعي وتضمين المتغيرات التكنولوجية عند

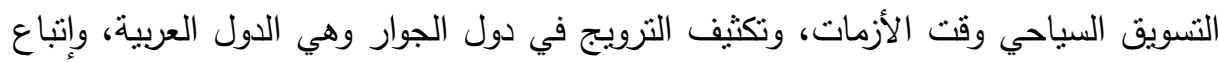
سياسة القيمة المضافة عند التسعير وقت الأزمات والتركيز على العلاقات العامة والإعلام كأهم عنصران للترويج السياحي وقت الأزمات لاى القطاع الحكومي وكل ما سبق يؤدي إلى الى على التسويق السياحي الفعال وقت الأزمات.

دراسة أحمد عادل محمود ؟ ؟ ب بعنوان أثر الأزمة المالية العالمية على حركة شركات السياحة فى مصر، تهدف الدراسة إلى التعرف على أثر هذه الأزمة على أنشطة

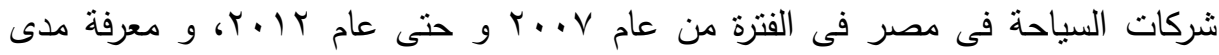
السلبيات التى لحقت بها و اكثر الأنشطة تضررا و التعرف على الخطوات و الحلول التى تم إنخاذها للحد من سلبيات هذه الأزمة على أنشطة شركات السياحة. أظهرت نتائج الدراسة: حدوث تأثثر سلبي علي شركات السياحة في مصر وأنشطتها المختلفة،

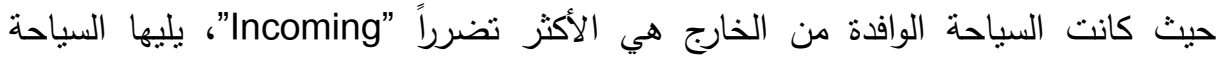
الداخلية، ثم حجز وإصدار تذاكر الطيران، ثم السياحة الدينية. كما أظهرت الدراسة إفتقار معظم شركات السياحة في مصر إلي خطة لمواجهة الأزمة، وإعتمادها علي الحلول والقرارات

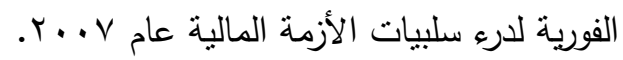


دراسة ثويب حسن سليمان ب ا • Y ب بعنوان دور الهوية السياحية فى تعزيز القدرة التنافسية للمقصد السياحى المصرى هدفت الدراسة إلى: - توضيح تعدد مكونات الهوية السياحية المصرية سواء مكونات الهوية النقافية ومكونات الهوية العمرانية وكذلك توضيح الهوية الإجتماعية للمقصد السياحى المصرى ومدى التتاغم بين تلاك المكونات لتشكل هوية متميزة للمقصد السياحى المصرى. - محاولة التعرف على مفهوم الهوية السياحية وتطبيقه على صناعة السياحة المصرية

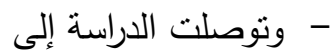
- الهوية فى شكلها العام هى الثكل المتميز لمجتمع ما وهى عميقة الجذور وتتتاقل من جيل

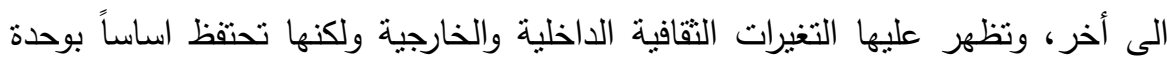
مستقرة - تُعد هوية المقصد السياحى فى كثثر من الأحيان جزء لا يتجزأ من مفهوم الصورة الذهنية للمقصد السياحى والتى تتضمن مجموعة من الخصائص أو الأبعاد الأساسية منها هو هو هائا

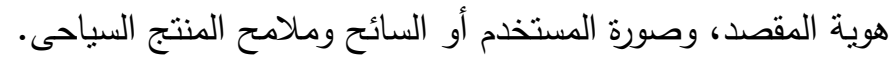
- تُعد مصادر المعلومات المتاحة عن المقصد السياحى عامل مؤثر فى تشكيل الصورة الذهنية لهوية المقصد السياحى

التعليق على الدراسات السابقة: تلاحظ ان اغلب الدراسات السابقة التى إطلعت عليها

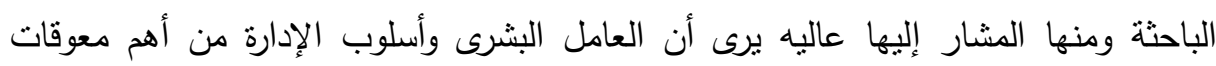

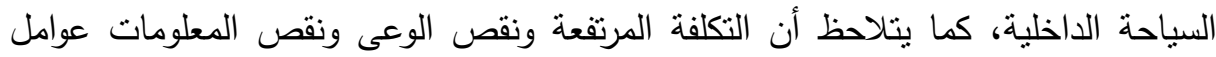

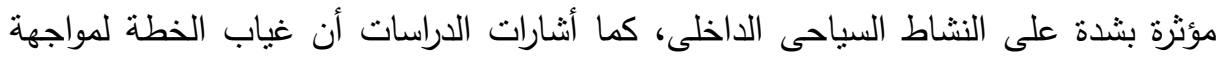
الأزمة التى تمر بها السياحة الداخلية من أسباب ظهور المعوقات المؤثرة على النشاط السياحى، كذلك إتققت أغلب هذه الدراسات فى نتائجها مع نتائج الدراسة الحالية. 


\section{الإجباءاهي المنهجية والمهيكانهية}

المجال المكانى: أجريت هذه الدراسة على مدينة شرم الثيخ بإعنبارها مدينة سياحية هامة

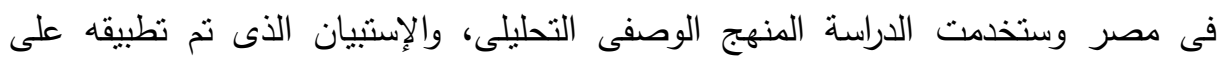

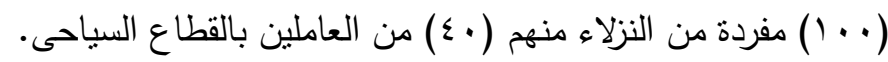

\section{أسوايت الصراسمة}

تعتمد الدراسة على نوعين من الأدوات هما:

الاستبيان الذى أجرته على عدد من العملاء نزلاء الفنادق فى مجال الدراسة الجغرافى وتشمل أسئلة عن البيانات اللأولية للعينة وأخرى تتعلق بمتغيرات الدراسة. الإستتبيان الأول الخاص بالمستقيدين من الخدمات السياحية

وصف الاستبيان: بعد قيام الباحثون بالإطلاع على الإستنيانات التى أجريت فى مجلئ مجال السياحة من خلال مجموعة الدراسات التى توصل إليها إطلاع الباحثة، رأت صياغة الاستبيان

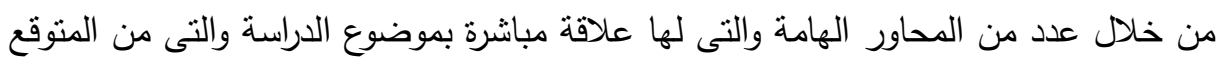
أن تحقق فروضها، وكانت أهم هذه المحاور هى:

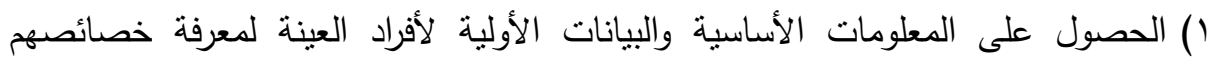
المختلفة من حيث السن والجنس والمستوى التعليمى والحالة الزواجية والدخل. r مدى وجود نوعية بالنشاط السباحى وتوعية بالأماكن والخدمات السياحية للسائح المحلى.

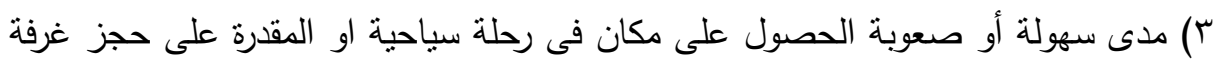
فى فندق.

ع) مدى مناسبة الإستقبال للسائح المصرى فى المنشأة السياحية ورضاه عن مستوى الإسنقبال

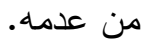
0) مستوى الخدمة والضيافة وتوافر الخدمات والمساعدة والراحة والأمن وملائمة الغرف والمرافق • 7) البرامج السياحية ومستوى الأداء فيها ودرجة الإهتمام بالسائح المصرى وتلبية نطلعاته. المجلد الثالث والثلاثون، الجزء الثالث، يونيو 17 . 
V صدق وثبات الاستبيان الخاص بالمستقيدين من الخدمات السياحية. الصدق: بعد إعداد صحيفتى الإستبيان لعملاء الفنادق والعاملين فى المجال السياحى بمدينة شرم الثيخ قامت الباحثة بعرضهما على مجموعة من الخبراء المحكمين وأثنار المحكمين

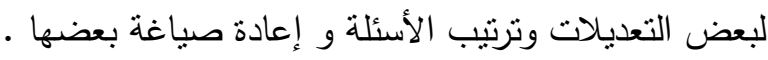
صدق الإتساق الاخلي للاستييان: تم حساب معاملات ارتباط كل بعد من أبعاد الاستبيان بالدرجة الكلية للاستبيان والتي نتجت عن نطبيق الاستبيان على عينة مبدئية من عينة الدراسة، وقامت الباحثة بحساب صدق الإتساق الداخلي ومعامل الارتباط المصحح كالآتي: جدول رقم(1): ثبات العبارات وصدق الاتساق الداخلي لأبعاد الاسنتيان

\begin{tabular}{|c|c|c|c|}
\hline معامل الارتباط & الإستبالي & قأَّنماة & أبعاد الاستبيان \\
\hline$\cdot, \vee \vee \top$ & $($ (**) $), 7) \leq$ & $\cdot, 7 \cdot 1$ & اتجاهات حركة السياحة الداخلية \\
\hline$\cdot, 7$ & $(* *) \cdot, \Sigma \curlyvee \wedge$ & $\cdot, T \leqslant r$ & البيئة الاقتصادية المحيطة بالسائحين المصريين \\
\hline$\cdot, 90$ & $(* *) \cdot, 9 \cdot \leq$ & $\cdot, 7 \cdot 9$ & البيئة الاجتماعية المحيطة بالسائحين المصريين \\
\hline$\cdot, 9 \leq$ & $(* *) \cdot, \wedge \wedge \wedge$ & $\cdot, T \leq r$ & درجة رضائهة المقدمة مسنوى جودة الدولة الخدمات \\
\hline-- & -- & $\cdot, \wedge \leqslant M$ & إجمالى الاستبيان \\
\hline
\end{tabular}

يتضح من الجدول السابق أن قيم معاملات الثبات جميعها قيم مقبولة حيث بلغت قيم

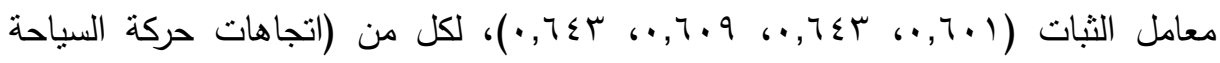
الداخلية، البيئة الاقتصادية المحيطة بالسائحين المصريين، البيئة الاجتماعية المحيطة

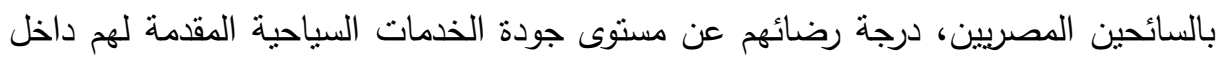

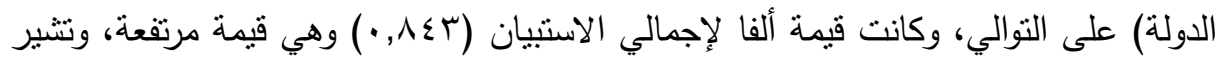
هذه القيم من معاملات الثبات إلى صلاحية الاستبيان للنطبيق وإمكانية الاعتماد على نتائجه والوثوق به.

الإستبيان الثانى: وكان عن إسنطلاع رأى العاملين فى السياحة عن المشكلات التى تواجهرم فى عملهم 
وقد تضمن هذا الإستبيان عدة نقاط أساسية من وجهة نظر الدراسة وقد تم صياغتها بعد الإطلاع على الإستبيانات فى الموضوعات ذات الصاة بموضوع البحث والتى توصل إلى إليها علم الباحثة وكان اهم هذه النقاط ما يلى: () البيانات الأساسية عن العاملين فى السياحة عينة البحث وقد شملت السن السن والجنس والمستوى التعليمى والحالة الزواجية والدخل والخبرة فى العمل والتدريب.

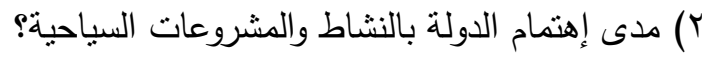

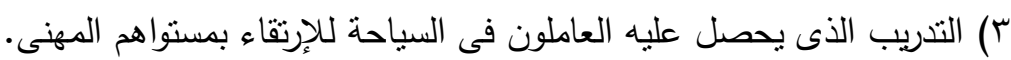
ء) التوعية بالأماكن السياحية والنشاط السياحى والخدمات والمميزات المختلفة للرحلات

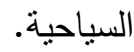
•) الإستثمار فى النشاط السياحى والمشكلات التى تواجه المستثمرين فى المشروعات

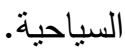
7) مدى مساهمة السياحة الداخلية فى حل أزمات السياحة. V أهم المعوقات التى نواجه السياحة فى مصر ومقترحات حل مشكلات هذا القطاع الحيوى.

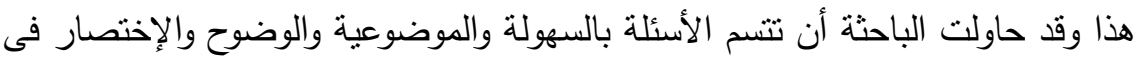
عدد الأسئلة قدر الإمكان حتى لا يكون الإستبيان طويلا فيصيب أفراد العينة بالملل فيؤثر ذلك على إستجابتهم. - مان. وقد كان عدد الأسئلة فى بداية الإستبيان الخاص بالعاملين فى مجال السياحةحول

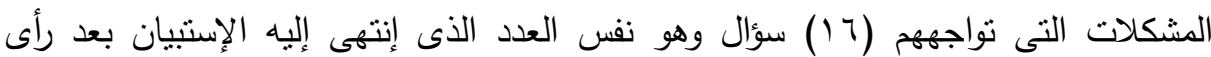

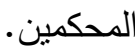

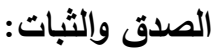
صدق الإستيّيان:بعد إعداد صحيفتى الإستبيان لعملاء الفنادق والعاملين فى الدجال السياحى بمدينة شرم الثيخ قام الباحثون بعرضهما على مجموعة من الخبراء الدحكمين وأنثار

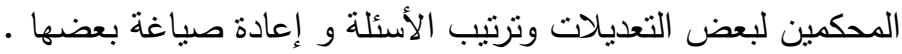


ثبات الاستيبان: للتحقق من ثبات الاستبيان استخدمت الباحثة معادلة ألفا كرونباخ

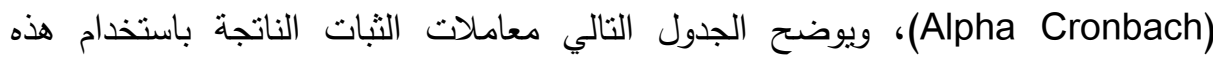

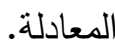

صدق الإتساق الاخلي للاستبيان: تم حساب معاملات ارتباط كل بعد من أبعاد الاستبيان بالدرجة الكلية للاستبيان والتي نتجت عن نطبيق الاستبيان على عينة مبلئية من عينة الدراسة، وقامت الباحثة بحساب صدق الإتساق الداخلي ومعامل الارتباط المصحح كالآتي: جدول رقم(ץ) ثبات العبارات وصدق الاتساق الداخلي لأبعاد الاستبيان

\begin{tabular}{|c|c|c|c|}
\hline معامل الارتباط & الأستباليان & أقيمة & أبعاد الاستبيان \\
\hline$\cdot, \sqrt{1} \times$ & $(* *) \cdot, 0 \leqslant 1$ & $\cdot, 0 \leqslant 7$ & اتجاهات حركة السياحة الداخلية \\
\hline$\cdot, 7$ & $(* *) \cdot, 79 \mathrm{~V}$ & $\cdot, \Sigma \wedge Y$ & البيئة الاقتصادية المحيطة بالسائحين المصريين \\
\hline$\cdot, 90$ & $(* *) \cdot, 7 \vee \wedge$ & $\cdot, 109$ & البيئة الاجتماعية المحيطة بالسائحين المصريين \\
\hline & $(* *) \cdot, 000$ & $\cdot, 01 \mathrm{~V}$ & درجة رضائئه اللمقدمة لهنوى داخل الدولة الخدمات \\
\hline-- & -- & $\cdot, 7 \leq 9$ & إجمالى الاستبيان \\
\hline
\end{tabular}

يتضح من الجدول السابق أن قيم معاملات الثبات جميعها قيم مقبولة حيث بلغت قيم

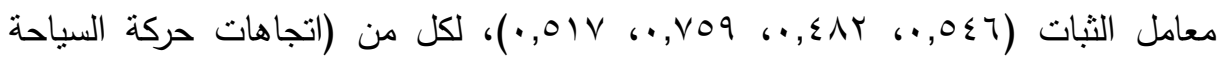

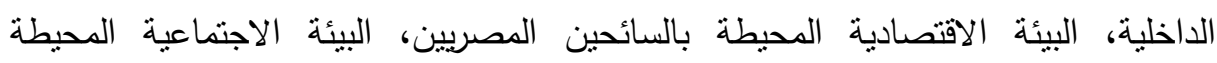

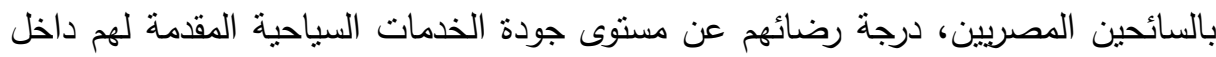

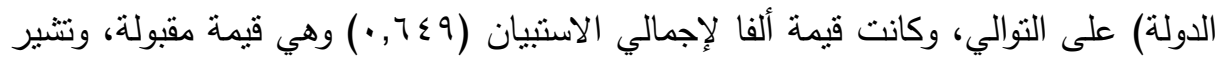
هذه القيم من معاملات الثبات إلى صلاحية الاستنيان للنطبيق وإمكانية الاعتماد على نتائجه

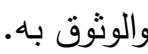

المقابلة المقتنة: وهى أداة ثقوم على لقاء الباحثة مباشرة مع عدد من العملاء وعدد من العاملين بالقطاع السياحى ممن تتطبق عليهم خصائص العينة توجه من خلالها أسئلة معدة سلفا وتتيح الفرصة للحصول على معلومات عميقة وواضحة عن موضوع السؤال كما تتيح للباحث الفرصة لملاحظة الثخص وإنفعالاته أثناء الإجابة على الأسئلة وتدوين هذهاته الملاحظات فى الإستمارة الخاصة بالمقابلة. 


\section{عينمة التواسمة}

تتكون عينة الدراسة من:

أولاً: عدد ( . . (1) مفردة من عملاء الفنادق والعاملين بها بشرم الثيخ، منهم ( • ب) من العملاء

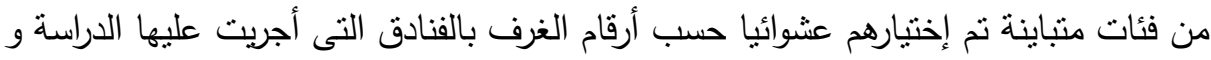

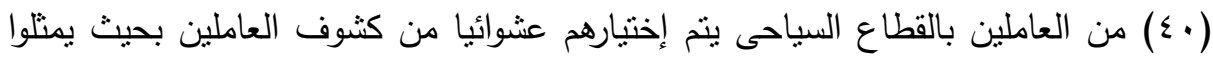

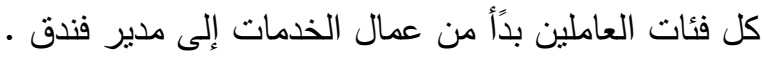
ثانياً: عدد (• () أفرد أجريت معهم مقابلة مقننة نصفهم من العملاء والنصف الأخر من فنائ العاملين بالقطاع السياحى بمدينة شرم الثيخ. ليكون العدد الكلى للعينة (• (1) مفردة) جدول رقم(r): يوضح خصائص عينة الدراسة من حيث العمر لئه

\begin{tabular}{|c|c|c|}
\hline النسبة المئوية & العدد & العمر \\
\hline$\% \leqslant \wedge$ & $\sum \wedge$ & آقل من Yo \\
\hline$\% r r$ & r & من צץ- ,ع \\
\hline$\% 10$ & 10 & من إ الي .7 \\
\hline$\% \varepsilon$ & $\varepsilon$ & آكثر من · T \\
\hline$\% 1 \ldots$ & $1 \ldots$ & اللجموع \\
\hline
\end{tabular}

يوضح الجدول رقم (1) خصائص عينة الدراسة العمرية حيث جاء الثباب دون سن

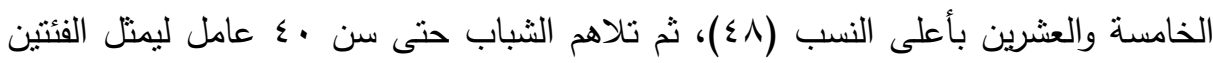

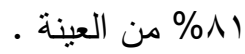

خصائص العينة: حددت الدراسة بعض الخصائص التى يجب نوافرها فى عينة الدراسة وهى كالأتى: -أن يتراوح سن العينة من 0 الاتى: - . -أن تتكون العينة من الذكور والإناث بنسب متقاربة قدر الإستطاعة. - أن يكون العميل من نزلاء الفنادق وقت إجراء الدراسة. - أن يكون العامل بالفندق مر عليه عام على الأقل بالقطاع السياحى. - أن نتمل العينة فنادق (خمس وثلاث نجوم وفنادق نجمنين). 
- أن يكون لاى مفردات العينة القبول لإتمام الإستبيان أو المقابلة وتستبعد كل إستمارة غير مكتملة.

-وقد أجريت الدراسة الميدانية فى الفترة من شهر يناير إلى شهر مارس عام 17 ــا،

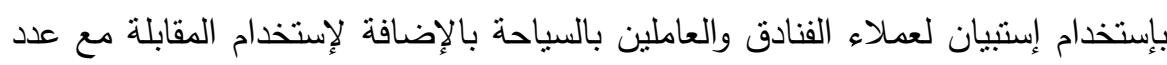

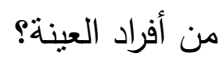

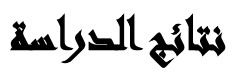

\section{أولاً: التحقق من صحة فرض الاراسة:}

الفرض الأول: هناك علاقة معنوية بين البيئة الاجتماعية المحيطة بالسائحين المصريين، ودرجة رضائهم عن مسنوى جودة الخدمات السياحية المقدمة لهم داخل الدولة. الجدول يوضح العلاقة بين البيئة الاجتماعية المحيطة بالسائحين المصريين ودرجة رضائهم عن مستوى جودة الخدمات السياحية المقدمة لهم داخل الدولة لئل

\begin{tabular}{|c|c|c|}
\hline 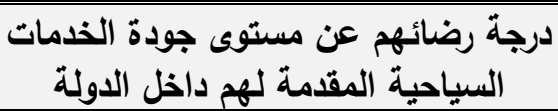 & & المتغيرات \\
\hline$(* *) \cdot, \wedge \leq 1$ & معامل الارتباط & \multirow{2}{*}{ البيئة الاجتماعية المحيطين } \\
\hline$\cdot, \ldots 1$ & الدلالة المعنوية & \\
\hline
\end{tabular}

بالنظر في الجدول السابق يتضح وجود علاقة ارتباطية ذات دلالة معنوية عند مستوى

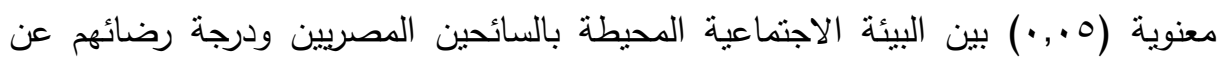
مستوى جودة الخدمات السياحية المقدمة لهم داخل الدولة حيث بلغت قيمة معامل الإرتباط

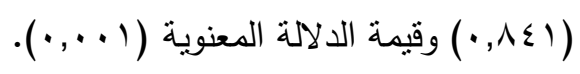
مما سبق يتحقى صحة القرض الأول. 


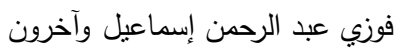

الفرض الثاني: هناك علاقة معنوية بين البيئة الاقتصادية المحيطة بالسائحين المصريين واتجاهات حركة السياحة الداخلية. الجدول يوضح العلاقة بين البيئة الاقتصادية المحيطة بالسائحين المصريين واتجاهات حركة السياحة الداخلية

\begin{tabular}{|c|c|c|}
\hline اتجاهات حركة السياحة & & المتغيرات \\
\hline$(* *) \cdot, \Sigma Y \leqslant$ & معامل الارتباط & \multirow{2}{*}{ البيئة الاقتصادية المحيطة بالسائحين } \\
\hline$\cdot, \cdots 1$ & الدلالة المعنوية & \\
\hline
\end{tabular}

بالنظر في الجدول السابق يتضح وجود علاقة ارتباطية ذات دلالة معنوية عند مستوى معنوية (0. , •) بين البيئة الاقتصادية المحيطة بالسائحين المصريين واتجاهات حركة السياحة

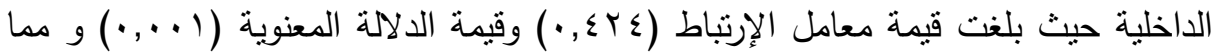
سبق يتحقق صحة الفرض الثاني. أهم نتائج الدراسة: (1) هناك علاقة معنوية بين البيئة الاقتصادية المحيطة بالسائحين المصريين واتجاهات حركة

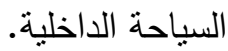
Y) هناك علاقة معنوية بين البيئة الاجتماعية المحيطة بالسائحين المصريين، ودرجة رضائهر عن مستوى جودة الخدمات السياحية المقدمة لهم داخل الدولة.

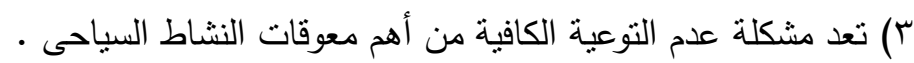

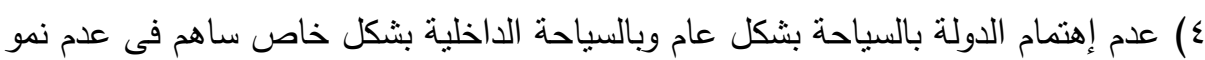
هذا النشاط بالصورة المتوقعة مقارنة بالإمكانات المتاحة. 0) عدم وضع برنامج واضح للرحلات السياحية وإعلام السائحين بهذا البرنامج. 7) غياب خطط وبرامج التسويق الجيد للمشروعات السياحية. V أوضحت غالبية العينة النقص الواضح فى تدريب العاملين بمجال السياحة وضعف التعليم

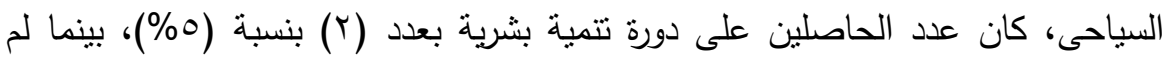

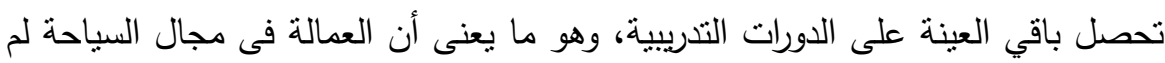




$$
\text { تحصل على تدريب مناسب أو على أى تدريب على الإطلاق مما بعنى تدنى مستوى }
$$

^) وعن أهم المشكلات التى تواجه المستقيدين من الخدمات السياحية فكانت كانت مشكلة

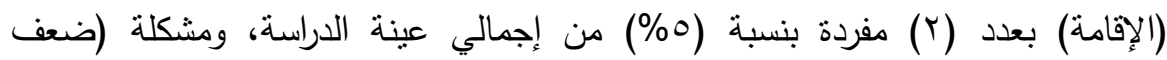

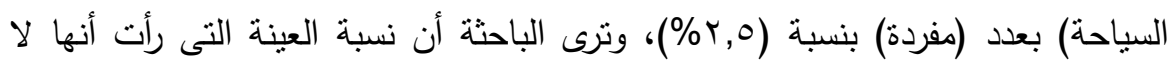

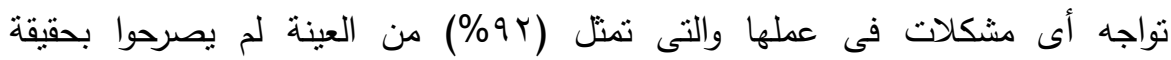
المشكلات التى تواجهرم وخاصة أن السياحة فى مصر فى الفترة الحالية تعانى بشكل

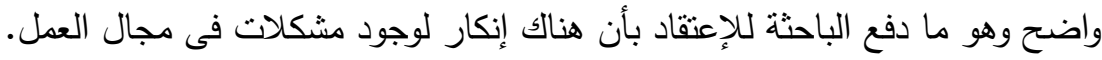

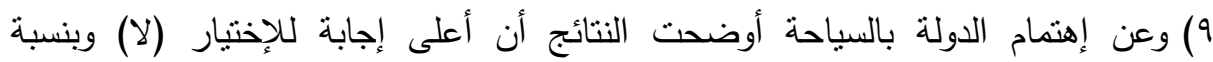

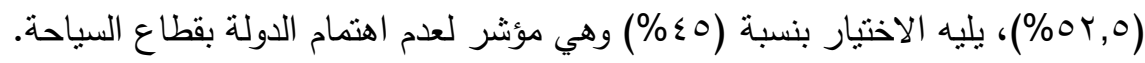
• ( ) غياب خطط الأسعار وعدم الرقابة على البائعين فى المناطق السياحية.

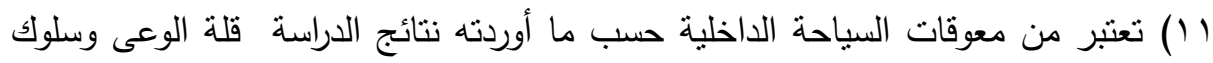
السائح المصرى وثقافته السياحية. r T أت عينة الدراسة أنه لا يوجد إهتمام بالسائح المصرى كما يحصل عليه السائح الأجنبى.

\section{نتائج المقابلة:}

- - تلاحظ تتوع المؤهلات العلمية لعينة الدراسة بينما كان جميعهم من الحاصلين على مؤهل عالى وواحد منهم فقط من الدارسين بمجال السياحة والفنادق. - كانت غالبية عينة الدراسة إجابتهم بلا على سؤال هل عملت بالسياحة بعد الخرج مباثرة. 1 . -

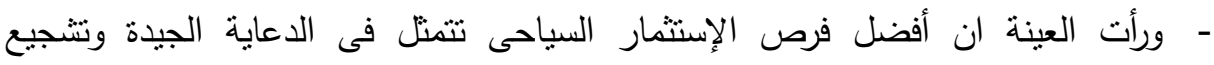
السائحين وخاصة العرب لتعويض نقص السياحة الإجنبية، والإهنمام بالرحلات السياحية

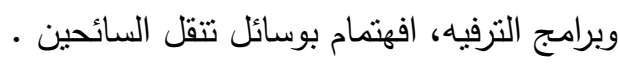


- مرأت العينة أن أهم ما يساعد على تحسين الخدمة السياحيةهو المصداقية فى التعامل مع السائحين، والدعاية والتسويق الجيد، وترديب العاملين بالمجال وتتمية مهارتهم، زيادة وعى لهى

- كانت مدة العمل باسياحة لأفراد العينة نتراوح بين عامين وعشرين عاما. - أوضح (،^\%) من العينة أنه لا نوجد قاعدة بيانات للأماكن السياحية.

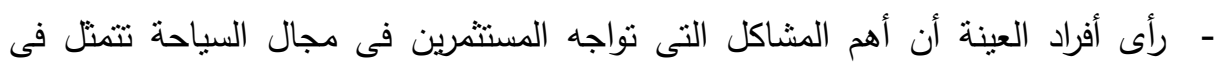
غياب الأمن وضعف الخدمات والعمليات الإرهابية وقلة التسهيلات للمستثرين الجادين. - أكدت عينة الدراسة عدم وجود قاعدة بيانات عن المشاكل التى نواجه المستثرين فى ولى مجال السياحة.

- معن أهم المشاكل التى تواجههم أعربوا أنها تتمثل فى تغيير فئة السائحين، وإستخدام أساليب سيئة فى الدعاية للسياحة، وثقافة السائح الدصرى التى يرونها غير متحضرة.

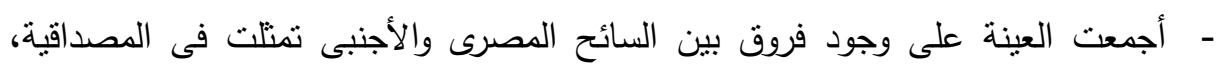

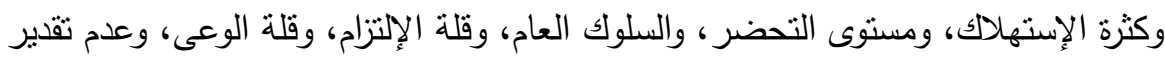

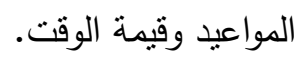

- - أوضحت جميع مفردات العينة أن هذه المشاكل السابقة لا يتم التعامل معها أو حلها.

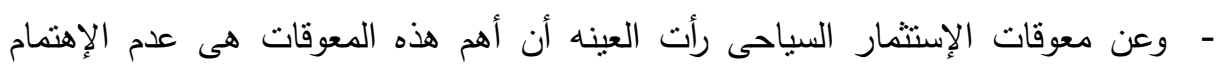
بالعاملين بالسياحة وغياب الأمن وكثرة الحوادث المرتبطة بالسياحة، وقلة التوات التوعية. - مرأت العينة أن الحل الأمتل لتحسين فرص الإستثمار السياحى تتمثل فى عودة السياحة الأجنبية حيث أن السياحة الداخلية فى رأيهم لا تعوض غياب الإن السائح الأجنبى.

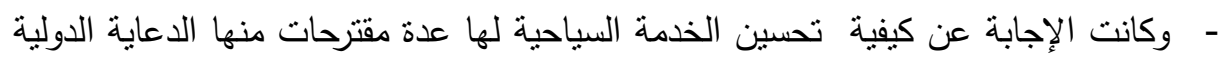
المدروسة وعودة المن وتدريب العاملين بالسياحة، والإهنمام بالتعليم السياحى، وتحسين طرق التسويق ورفع كفاءة البنية التحتية للمشروعات السياحية. 
وفيما يلى بعض الجداول التى توضع بعض نتائج الدراسة

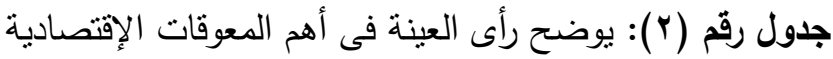

\begin{tabular}{|c|c|c|}
\hline النسبة المئوية & العدد & السبب \\
\hline \%ऑा & 71 & إرتقاع تكالبف الإقامة \\
\hline \%YY & Tr & إرتفاع تكاليف الإنتقالات \\
\hline$\% \backslash \mathrm{V}$ & IV & الإستخلال الإقتصادى \\
\hline
\end{tabular}

يوضح الجدول رقم (Y) أهم المعوقات الإقتصادية من وجهة نظر عينة الدراسة، وإحتل إرتفاع التكاليف أعلى نسبة وأوضحت المقابلة أن العملاء يرون أن التكاليف السياحية بمدينة شرم الثيخ تقل قليلا عن تكاليف رحلة إلى تركيا مثلا، وأن الثكل الاجتماعى سيختلف كثيرا عندما يقضى السائح عطلته بتركيا مثلا عنه لو قضاها بشرم الثيخ مع فارق مادى ليس

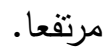
وجائت مصاريف الإنتقال فى المركز الثانى وأوضحت المقابلة أن السائح لا يقصد فقط الإنتقال من محافظته إلى شرم الثيخ بل يقصد رحلات السفارى والإنتقالات الداخلية فى الإلى المدينة وللمناطق السياحية خارجها. جدول رقم(؟): يوضح رأى العينة فى أهم المعوقات الداخلية

\begin{tabular}{|c|c|c|c|}
\hline النسبة المئويدة & العدد & السبب & \\
\hline$\% \varepsilon r$ & $\Sigma \Gamma$ & غياب الوعى السياحي & 1 \\
\hline$\%$ \% & $r \cdot$ & أسلوب معاملة السائح المصرى & r \\
\hline \%Tr & TY & بعد مدينة شرم الثيخ عن الوادى & $r$ \\
\hline$\% 1$. & T. & ألسلوكيات الخاطئة & $\varepsilon$ \\
\hline
\end{tabular}

يوضح الجدول أهم الأسباب الإجتماعية التى تواجه السياحة الداخلية وجاء فى مقدمنها غياب الوعى السياحى حيث أكد r؟\% من العينة أن غياب الوعى والتعريف بالأماكن

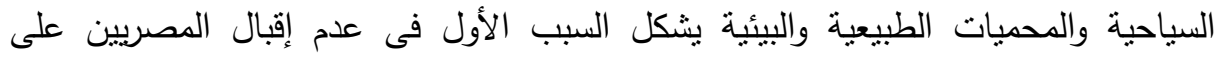

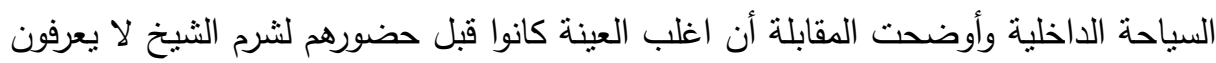

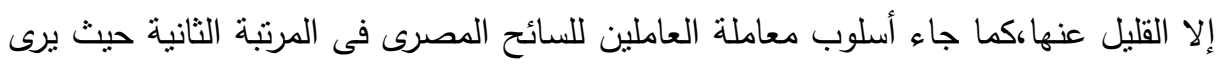

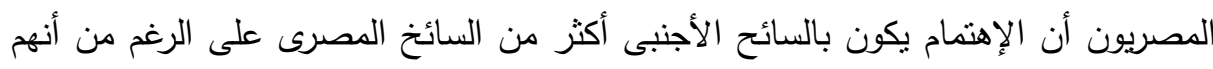
نزلاء بنفس الفندق. 


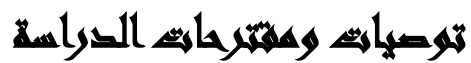

- توصى الدراسة بالإهتمام بوضع إستراتيجية عامة وشاملة للنشاط السياحى بما يحقق أهداف هذا النشاط ويساعد فى النمو .

- الإهتمام بضرورة تسعير الخدمات السياحية والفندقية بما بتتاسب مع الوضع الإقتصادى اللمواطن المصرى ويشجعه على السياحة الداخلية. - وضع برامج توعية مدروسة يمكنها الوصول لجميع شرائح المواطنين بما يشجع على قيام المواطن بالسباحة الداخلية - توفير الأمن بصورة تشجع المواطن على حرية الإنتقال إلى الأماكن السياحية وتحميه من

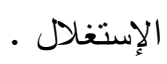

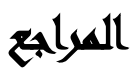

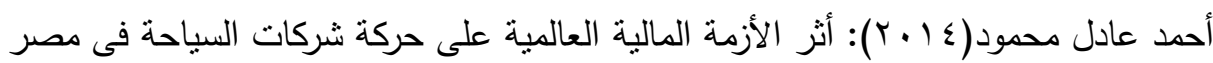

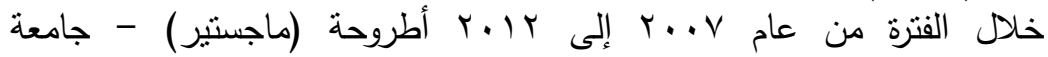
المنصورة. كلية السياحة والفنادق.

أسامة عبد الرحمن( • ( • ب): السياحة -إمكانيات ومعالم. دار زهور المعرفة والبركة -الجيزة

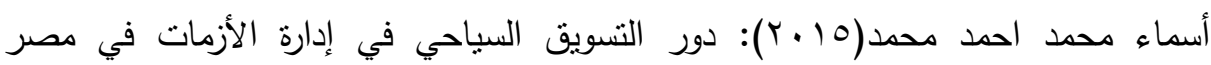

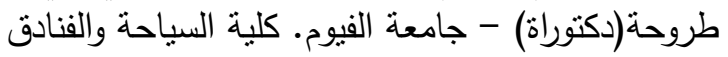

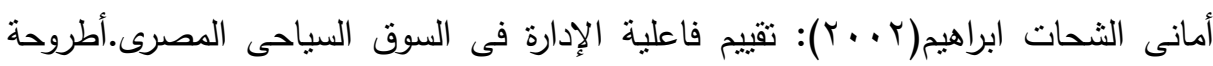
(دكتوراه ) - جامعة حلوان. كلية السياحة والفنادق.

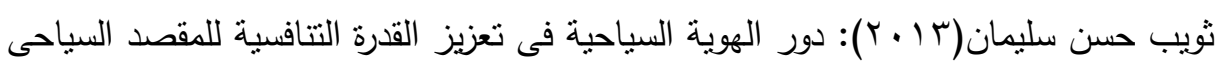
المصرى اطروحة (ماجستير) - جامعة حلوان. كلية السياحة والفنادق.

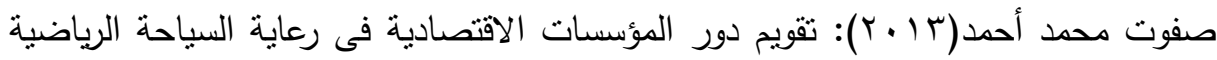
بمصر اطروحة(دكتوراة)-جامعة الأسكندرية. كلية التربية الرياضية بنية بنين.

غادة محمود على(991 (1)): المخل إلى عالم السياحة والسفر ـ مطبعة كلية السياحة والفنادق

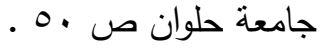


وفاء أحمد عبد الله(ب19 1): حول العلاقة بين السياحة والبيئة المعاصرة مؤتمر القادة القاهرة ص ص

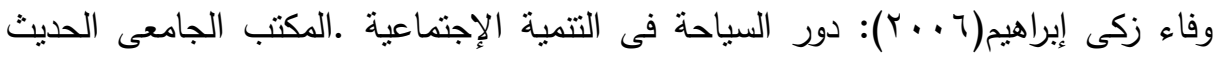

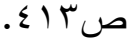

غنيمة عبدالفتاح(1997 (): السياحة قاطرة التتمية لمصر المعاصرة، الإسكندية، دار الفنون العلمية.

نوفل(ب991): "البرامج السياحية في الإذاعة المسموعة، رسالة ماجستير (غبر منشورة)، كلية

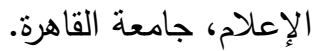

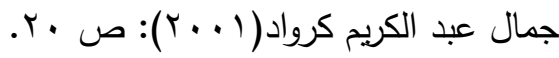

مصطفى يوسف كافي(ع ( • ץ): "|قتصاديات البيئة"، دار مؤسسة رسلان للطباعة والنشر

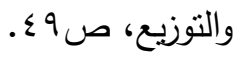

نجم طه(919 ()): "الصحافة المصرية وتتكيل الوعي الاجتماعي"؛ رسالة ماجستير (غير منشورة)، كلية الآداب، جامعة الإسكندرية.

فهي عادل(1990): دور التلفزيون المصري في تكوين الوعي الاجتماعي ضد الجريمة،

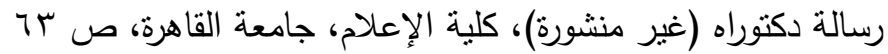

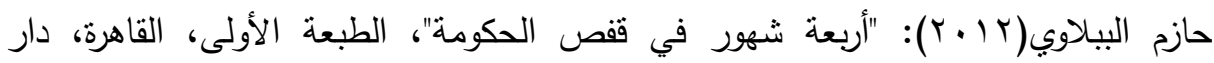

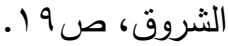

Hiemastra,s.j.(1987): factors affecting the supply and demand for employment in the lodging industry . Hospitality Education and research Journal, Vol.11 no 2 ,pp135-141.

Stattery,p. (2002): Finding the Hospitality industry. Journal of Hospitality,Leisure, Sport and Tourism Education.1.(1) :pp.157-168.

"Turmer and Y.reisinger" (cross- cultural differences in tourism), Cairo, 1987. 
فوزي عبد الرحمن إسماعيل وآخرون

\title{
SOCIAL AND ECONOMIC OBSTACLES DOMESTIC TOURISM \\ STUDY AT DIFFERENT SOCIAL STRATA
}

Ismail, F.A. ${ }^{(1)}$; Lateef, Hoda, S. ${ }^{(2)}$ and Abu Said, Mona, Z. S..$^{(3)}$ 1) Faculty of Girls, Ain Shams University 2) Department of Tourism and Hotels, Sheraton Institute 3) Yanbu Tourism Company

\begin{abstract}
The study deals with the social and economic handicaps domestic tourism, Tourism is the most important Egyptian national income sources, especially their contribution as a source of foreign currency on the one hand and the reduction of unemployment and provide job opportunities on the other hand, which made the subject of a study of domestic tourism importance in general to face the constraints faced by, the study by reading the theoretical perspectives that address the social and economic constraints affecting domestic tourism to figure out ways to activate this kind of tourism activity in terms of enriching the economic side and the promotion and employment on the one hand and the definition of citizen effects of his country and its heritage and natural and national wealth, on the other hand to support belonging to the homeland. The researcher used the descriptive analytical approach and tools were the questionnaire and interview.

As for the field of spatial researcher Sharm El-Sheikh was chosen as one of the tourist cities, and for the field of human was a sample of customers in hotels with the assistance of a number (100) single distributed as follows (60 clients from different categories, and (40) Single from hotel personnel, and the trend is theoretical which is the starting point of the study is the functional constructivism.
\end{abstract}

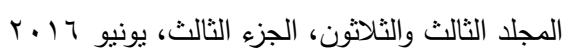


- The most important Altnaij clarified by statistical analysis of the following:

- That the most important constraint is the high cost of domestic tourism, compared to tourism in some countries in the region.

- Declined the treatment of Egyptian tourists compared to the level of the foreign counterpart.

- The lack of a clear strategy for domestic tourism in spite of its importance.

- Lack of awareness and lack of information provided to the Egyptian tourist places which can had, and price plans.

- One of the main recommendations follows:

- The study recommends the development of public attention and a comprehensive strategy for Tourism Activity in order to achieve the objectives of this activity and help growth.

- Attention to the necessity of tourism and hotel pricing of services commensurate with the economic situation of the Egyptian citizen and encourage domestic tourism.

- Develop a deliberate outreach programs can access for all segments of citizens, including citizens are encouraged to do domestic tourism. 